\title{
Renal cell carcinoma with Xp11.2 translocation/TFE3 gene fusions-experience from a tertiary care hospital in Kerala, India
}

Zuhara Shemin $^{1 *}$, Sreekala Sreehari ${ }^{2}$ and Annie Jojo ${ }^{3}$

*Correspondence: zuharasalman@gmail.com

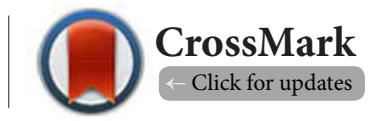

${ }^{1}$ Consultant Pathologist, Gokula Metropolis Clinical Laboratories, Basement, M S Ramaiah Hospital, Bangalore, India.

${ }^{2}$ Assistant Professor, Department of Pathology, Amrita Institute of Medical Sciences, Kochi, Kerala, India.

${ }^{3}$ Professor and HOD, Department of Pathology, Amrita Institute of Medical Sciences, Kochi, Kerala, India.

\begin{abstract}
Renal cell Carcinoma (RCC) with Xp11.2 translocation/TFE3 (Transcription factor E3) gene fusions comprise at least one-third of the cases of pediatric RCC. The significance of identifying these cases is that, VEGFR (Vascular Endothelium derived Growth Factor)-targeted therapies and mTOR (mechanistic target of rapamycin) inhibitors seems to be active in the treatment of Xp11.2 translocation RCC. However, only few studies are available regarding this rare malignancy and as a result prognosis remains controversial. We present 2 cases of Xp11.2 RCC reported in our institute with a glimpse to the morphological patterns, ImmunoHistoChemistry (IHC) studies and cytogenetics.
\end{abstract}

Conclusion: RCC with Xp11.2 translocation/TFE3 gene fusion is a rare pediatric tumour for which the treatment options are on the advancing edge, based on which the prognosis can be improved.

Keywords: Xp1 1.2 translocation/TFE3 gene fusions, VEGFR-targeted therapies and mTOR inhibitors, renal cell carcinoma

\section{Introduction}

Renal Cell Carcinoma (RCC) with Xp11.2 translocation/TFE3 gene mutation is most common in children and young adults of average age 20 years. The female to male ratio -2.5:1 [2]. $90 \%$ cases involves transcription factor E3 (TFE3) located on Xp1 1.2. The most common fusions are ASPL (Alveolar Soft Part Sarcoma Like)-TFE3 and PRCC (Papillary RCC)-TFE3. Another rare group - $[\mathrm{t}(6 ; 11)(\mathrm{p} 21 ; \mathrm{q} 12)]$ involving transcription factor EB (TFEB). TFE3 nuclear staining is specific for the Xp11.2 translocation and nuclear TFEB staining is specific for $[t(6 ; 12)$ (p21; q12)] $[1,3,5,6]$. Fusion gene products disrupt the mitotic spindle leading to malignancy [3]. VEGFR-targeted therapies and mTOR inhibitors seem to be active in Xp11 translocation RCC $[3,6]$. The clinical efficacy of new front-line multityrosine kinase inhibitors that target the vascular endothelial growth factor pathway (sunitinib, sorafenib) and agents that target the mTOR pathway (temsirolimus) have improved the outcome for adults with RCC $[7,8]$. Hence identification of these cases helps in impoving prognosis.

\section{Case presentation}

\section{Case 1}

A $21 \mathrm{yr}$ old lady was referred to Amrita Institute of medical Sciences with history of right sided abdominal discomfort and pain. There was no history of hematuria or urinary tract infection. Abdominal Examination revealed a palpable mass in the right hypochondrium. CT scan of the abdomen \& pelvis showed a large partially cystic mass of $9 \times 8 \mathrm{~cm}$ size, Bosniak type 3 , arising from the anterior portion of right kidney. Subsequently she underwent Right open Radical Nephrectomy.

\section{Histopathology}

We received a Right Nephrectomy Specimen with perinephric fat and Hilar node. Cut surface of the kidney showed a well encapsulated, unilocular cyst, whole measuring $9 \times 7.5 \times 7 \mathrm{~cm}$, involving mid and lower pole of kidney. There were grey brown solid areas with focal areas of haemorrhage.

Microscopy: The histopathological sections showed a well encapsulated cystic neoplasm composed of cells arranged in 
papillary pattern, and alveolar and nesting patterns. Some papillary cores showed foamy histiocytes The tumour cells had abundant clear to eosinophilic cytoplasm, discrete cell borders, vesicular chromatin and prominent nucleoli appreciable at 40x (Furhman Grade 2). Psammoma bodies were frequent. The cystic areas were lined by similar cells. Mitosis is occasional. Necrosis \& hyaline nodules were also seen focally. Vascular emboli were also seen. Adjacent kidney shows cortical glomerulosclerosis. Hilar lymph node showed neoplastic infiltrate in 1/3 lymphnodes (Figure 1).

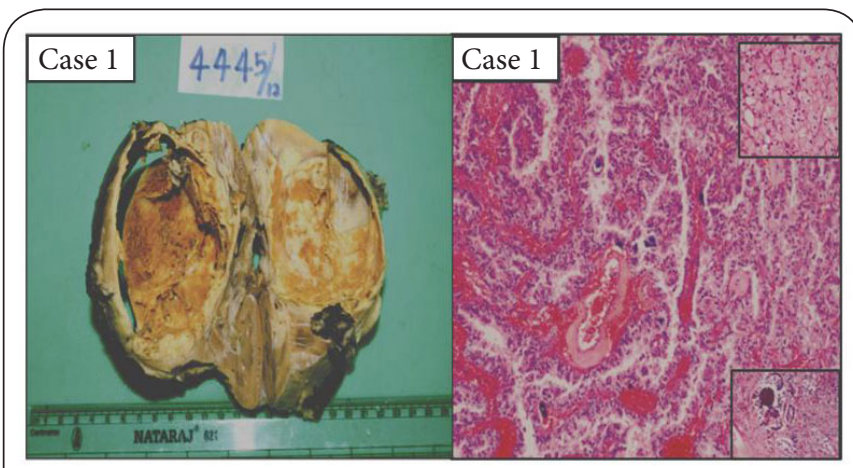

Figure 1. Gross image with Lesion mea: $9 \times 7.5 \times 7 \mathrm{~cm}$ (Left) and Microscopy of lesion (Right) with features of papillary RCC with foamy macrophages (inset), psammomma bodies \& Lymph Node metastasis (inset) (H\&E stain, 10x, inset 40x).

Hence a diagnosis of Renal cell carcinoma, with Xp11.2 translocation like features and lymph node metastasis (1/3) was made. IHC and TFE gene mutation study/Xp11.2 Translocation studies were suggested for confirmation. TNM staging: pT2N1Mx.

\section{Case 2}

A 17year old girl, was referred to Amrita Institute of Medical Sciences with history of total painless hematuria associated with clots in urine, along with right sided abdominal pain There was no relevant past history. Abdominal Examination was unremarkable. CTscan of the abdomen showed a well defined large lesion, of size $3 \times 2.5 \times 4 \mathrm{~cm}$ at lower pole of right kidney Subsequently she underwent Laparoscopic Right Radical Nephrectomy.

\section{Histopathology}

We received "Right radical nephrectomy" specimen. Cut section showed a well encapsulated grey white to yellowish white solid and cystic lesion measuring $3 \times 3 \times 5 \mathrm{~cm}$ in the mid pole. The lesion was soft and granular. Background renal parenchyma was unremarkable. No adrenals or Lymph nodes were identified.

Microscopy: The sections from the kidney show a neoplasm composed of cells arranged in papillary pattern. Some of the papillae showed central core of foamy histiocytes. The cells had abundant clear to eosinophilic cytoplasm, discrete cell borders, vesicular chromatin and prominent nucleoli. Psammoma bodies and hyaline nodules were seen. The cystic areas were lined by similar cells. Mitosis is occasional. Necrosis was absent. Adjacent kidney shows cortical glomerulosclerosis, occasional tubular red cell casts and patchy lymphocytic infiltration was seen in the interstitium (Figure 2).

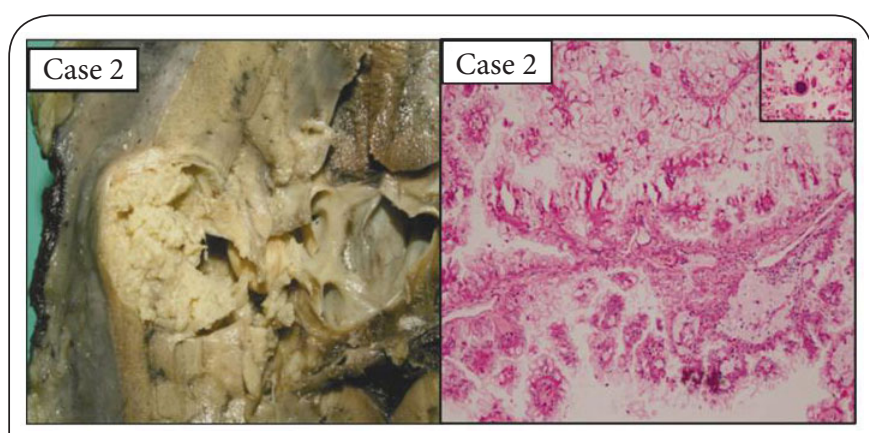

Figure 2. Cross section of the tumour grossly (left) with microscopic picture (right) (H\&E stain, 40x) of the same with psammoma bodies (inset-H\&E stain, 40x).

Hence we made a diagnosis of Renal cell carcinoma, with differentials between RCC with Xp11.2 translocation and papillary RCC, type2. IHC and cytogenetic studies for TFE3. gene mutation study/Xp11.2 Translocation studies were suggested for confirmation. TNM staging -pT1bNxMx.

\section{IHC (Immunohistochemistry)}

$\mathrm{IHC}$ studies from both cases favoured a diagnosis Renal cell carcinoma with Xp11.2 translocation (Figure 3).

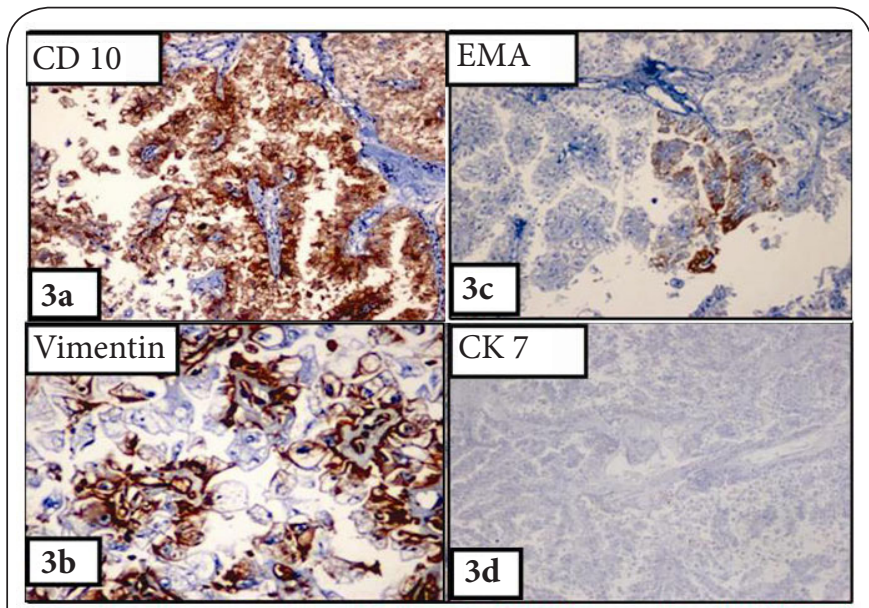

Figure 3. IHC results of case 1. IHC was done on the tumour tissue (a). CD10 stain-positive (10x). (b). Vimentin stainpositive (10x). (c). EMA stain-Focal positive (10x). (d). CK7 stain-negative $(4 \mathrm{x})$. The results are consistent with findings for RCC with Xp11.2 translocation. The results were the same for case 2 also, hence not included. 
Shemin et al. Journal of Histology \& Histopathology 2015,

\section{Cytogenetic studies}

Cytogenetic Analysis was done at Johns Hopkins Reference laboratories, USA. Immunostains showed that tumour cells were positive for TFE3, but negative for cathepsin-K. FISH analysis showed $55 \%$ (case 1 ) and $36.7 \%$ (case 2 ) of cells to have split TFE3 signal, supporting a diagnosis of translocation renal cell carcinoma in both cases. Hence a final diagnosis was made as follows.

Case 1: Renal cell carcinoma with Xp11.2 translocation/TFE3 gene fusion, pTNM-pT2N1Mx.

Case 2: Renal cell carcinoma with Xp11.2 translocation/TFE3 gene fusion, pTNM-pT1bNxMx.

\section{Discussion}

RCC with Xp11.2 TRANSLOCATION/ TFE3 gene mutation is most common in children and young adults of average age 20 years. The female to male ratio $-2.5: 1$ [1]. 90\% cases involves transcription factor E3 (TFE3) located on Xp11.2. The most common fusions are ASPL TFE3 and PRCC-TFE3. Another rare grp - $[\mathrm{t}(6 ; 11)(\mathrm{p} 21 ; \mathrm{q} 12)]$ involving transcription factor EB (TFEB) [1]. TFE3 nuclear staining is specific for the Xp11.2 translocation and nuclear TFEB staining is specific for $[t(6 ; 12)$ $(p 21 ; q 12)][1,3,6]$. Fusion gene products disrupt the mitotic spindle leading to malignancy [3]. Grossly they are most commonly tan-yellow, and often necrotic and haemorrhagic $[\mathbf{1 , 2}]$.

Microscopically are characteristised by papillary, nested and compact (solid) patterns of growth [1,2]. 2 different mutations are seen. Morphology is slightly different for the two groups.

ASPL-TFE3: Microscopically a mixture of large, clear cells with granular eosinophilic cytoplasm with large nuclei vesicular chromatin, prominent nucleoli, discrete cell borders are seen. Psammoma bodies and intracytoplasmic hyaline droplets are frequent [1].

PRCC-TFE3: Cells have less abundant cytoplasm, fewer psammoma bodies, hyaline nodules with more compact and nested architecture [1].

\section{IHC (Immunohistochemistry)}

IHC studies usually show RCC Ag, CD10-consistently positivity, Vimentin-variable positivity, and Racemase, E-cadherin and melanoma associated antibodies positivity $[5,7]$. However, TFE3 and TFEB immunostains are SENSITIVE and SPECIFIC [7]. Cathepsin-K immunoreactivity distinguishes MiTF/TFE family renal translocation carcinomas from TFEB [9]. FISH, $P C R$ is confirmatory.

\section{Cytogenetics}

This image shows characteristic translocation detected by cytogenetic analysis Figure 4. Following table helps to differentiate translocation associated RCC from Clear cell RCC with papillary areas and Papillary RCC with IHC studies (Table 1).

\section{Prognosis}

Controversy exists regarding the prognosis of patients with

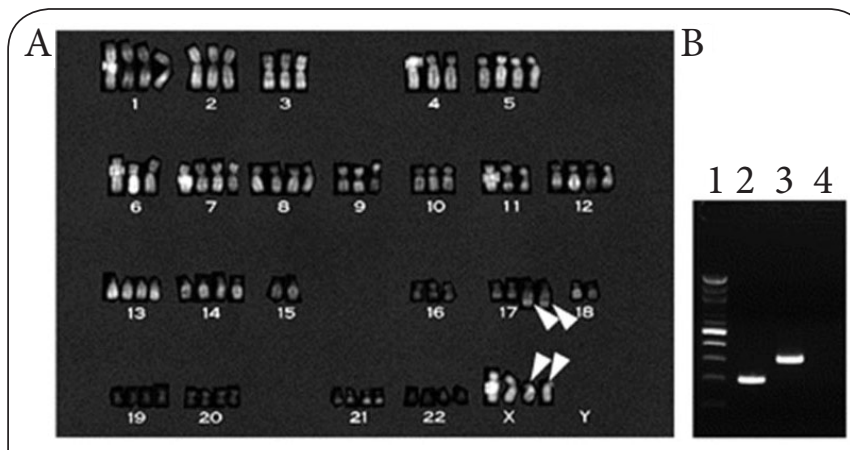

Figure 4. The translocation involving the short arm (A) of chromosome $\mathrm{X}$ and Chromosome 17 (shown by arrows). Also multiple chromosomal trisomies and duplications are also seen. (B) demonstrates the translocation with PCR (Polymerase Chain Reaction) technology.

Table 1. Differential diagnosis.

\begin{tabular}{llll}
\hline & Translocation carcinoma & Clear cell RCC & Papillary RCC \\
\hline CK 7 & Negative & Negative & Positive \\
CD10 & Positive & Positive & Positive \\
EMA & Negative & Positive & Positive \\
\hline
\end{tabular}

Xp11.2 RCC. Its likely to present with tumors at higher stages and also those with hematogenous metastases seem to have a dismal prognosis $[5,8,9]$. However in the majority of cases, there has been no evidence of disease following resection. VEGFR-targeted therapies and mTOR inhibitors seem to be active in Xp11.2 translocation RCC [3].

\section{Conclusion}

By highlighting the significance of detecting these cases, as targeted therapy is available. More studies and data are required, especially in the Indian as well as Asian Scenario, for assessing the prognosis of this disease.

\section{List of abbreviations}

TFE3: Transcription factor E3

IHC: ImmunoHistoChemistry

VEGFR: Vascular Endothelium derived Growth Factor

mTOR: Mechanistic target of rapamycin

TFEB: Transcription factor EB

\section{Competing interests}

The authors declare that they have no competing interests.

Authors' contributions

\begin{tabular}{|l|c|c|c|}
\hline Authors' contributions & ZS & SS & AJ \\
\hline Research concept and design & $\checkmark$ & $\checkmark$ & $\checkmark$ \\
\hline Collection and/or assembly of data & $\checkmark$ & $\checkmark$ & $\checkmark$ \\
\hline Data analysis and interpretation & $\checkmark$ & $\checkmark$ & $\checkmark$ \\
\hline Writing the article & $\checkmark$ & $\checkmark$ & $\checkmark$ \\
\hline Critical revision of the article & $\checkmark$ & $\checkmark$ & $\checkmark$ \\
\hline Final approval of article & $\checkmark$ & $\checkmark$ & $\checkmark$ \\
\hline
\end{tabular}


Shemin et al. Journal of Histology \& Histopathology 2015,

http://www.hoajonline.com/journals/pdf/2055-091X-2-6.pdf

\section{Acknowledgement}

The authors would like to thank Dr. Appu Thomas, HOD,

Department of Urology, Amrita Institute of Medical Sciences, India for supporting the article.

\section{Publication history}

Editor: Lingyan Wang, Oregon Health \& Science University, Portland.

EIC: Giuseppe Musumeci, University of Catania, Italy.

Received: 01-Nov-2014 Final Revised: 21-Feb-2015

Accepted: 20-Mar-2015 Published: 30-Mar-2015

\section{References}

1. WHO Pathology and Genetics of Tumours of the Urinary System and Male Genital Organs. 2004; 37-38.

2. Srigley JR and Delahunt B. Uncommon and recently described renal carcinomas. Mod Pathol. 2009; 22 Suppl 2:S2-S23. | Article I PubMed

3. Sternberg's Diagnostic Pathology. $5^{\text {th }}$ Edn.

4. Camparo P, Vasiliu V, Molinie V, Couturier J, Dykema KJ, Petillo D, Furge KA, Comperat EM, Lae $M$ and Bouvier $R$ et al. Renal translocation carcinomas: clinicopathologic, immunohistochemical, and gene expression profiling analysis of $\mathbf{3 1}$ cases with a review of the literature. Am J Surg Pathol. 2008; 32:656-70. | Article | PubMed

5. Argani P and Ladanyi M. Translocation carcinomas of the kidney. Clin Lab Med. 2005; 25:363-78. | Article | PubMed

6. Wu A, Kunju LP, Cheng $L$ and Shah RB. Renal cell carcinoma in children and young adults: analysis of clinicopathological, immunohistochemical and molecular characteristics with an emphasis on the spectrum of Xp11.2 translocation-associated and unusual clear cell subtypes. Histopathology. 2008; 53:533-44. | Article | PubMed

7. Geller JI, Argani P, Adeniran A, Hampton E, De Marzo A, Hicks J and Collins $\mathrm{MH}$. Translocation renal cell carcinoma: lack of negative impact due to lymph node spread. Cancer. 2008; 112:1607-16. | Article | PubMed

8. Selle B, Furtwangler R, Graf N, Kaatsch P, Bruder E and Leuschner I. Population-based study of renal cell carcinoma in children in Germany, 1980-2005: more frequently localized tumors and underlying disorders compared with adult counterparts. Cancer. 2006; 107:2906-14. I Article | PubMed

9. Martignoni G, Pea M, Gobbo S, Brunelli M, Bonetti F, Segala D, Pan CC, Netto G, Doglioni C, Hes O, Argani P and Chilosi M. Cathepsin-K immunoreactivity distinguishes MiTF/TFE family renal translocation carcinomas from other renal carcinomas. Mod Pathol. 2009; 22:1016-22. | Article | PubMed

\section{Citation:}

Shemin Z, Sreehari S and Jojo A. Renal cell carcinoma with Xp11.2 translocation/TFE3 gene fusions -experience from a tertiary care hospital in Kerala, India. J Histol Histopathol. 2015; 2:6.

http://dx.doi.org/10.7243/2055-091X-2-6 